\title{
EQUITY CONSIDERATIONS IN HEALTH CARE: AN AXIOMATIC BARGAINING APPROACH*
}

\author{
Xavier Cuadras-Morató, Universitat Pompeu Fabra. Barcelona \\ Department of Economics and Centre for Health Economics \\ José-Luis Pinto-Prades, Universitat Pompeu Fabra*. Barcelona \\ Department of Economics and Centre for Health Economics \\ José-María Abellán-Perpiñán, Universidad de Murcia
}

April 2000

\begin{abstract}
The general issues of equity and efficiency are placed at the center of the analysis of resource allocation problems in health care. We examine them using axiomatic bargaining theory. We study different solutions that have been proposed and relate them to previous literature on health care allocation. In particular, we focus on the solutions based on axiomatic bargaining with claims and suggest that they may be particularly appealing as distributive criteria in health policy. Finally, we present the results of a survey that tries to elicit moral intuitions of people about resource allocation problems and their different solutions.
\end{abstract}

Key words: QALYs, equity, claims, axiomatic bargaining, resource allocation

\footnotetext{
* We thank Carmen Herrero, Aki Tsuchiya and two anonymous referees for very useful comments. The usual disclaimer applies. Financial support from the Spanish government (SEC98-0296-C04-04) is gratefully acknowledged.

* Corresponding Author. Address: Department of Economics, Ramon Trias Fargas 25-27 08005 Barcelona. Fax 34935421746 Tel. 34935422638 email: jose.pinto@econ.upf.es.
} 


\section{Introduction}

The general issues of equity and efficiency are placed at the center of the analysis of the resource allocation problems in health care. Given some amount of resources to be spent on health care, an efficient allocation is defined as an allocation that lies in the utility possibility frontier or, in other words, satisfies the standard definition of Pareto optimality. In general, there are many such efficient points. The question we ask in this paper is how to choose one among all these options. Inevitably, the choice of one of these efficient points as the socially most desirable will imply value judgments which must be supported by equity principles which evaluate the appropriateness of its distributional consequences. The dominant, if not the only, criterion used in health care evaluation is health maximization (i.e. maximization of the number of QALYs, maximization of prevented strokes, etc.). The equity principle that lies behind this particular criterion is that all health improvements have exactly the same social value independently of the characteristics of the recipients of the benefits. One of the main sources of controversy caused by the use of the health maximization criterion is its distributional implications. This is what, among other things, motivates our attention on other criteria proposed in the literature.

Health maximization may lead to very uneven distributions of health. If society cares about this, then other principles (see Olsen (1)) more in line with social accepted values ought to be applied to solve the problem of resource allocation. Using a social welfare function (SWF), which aggregates individual utilities into social utility, is a strategy first proposed by Wagstaff (2) in the field of health economics in order to incorporate social concerns about equality to policy making. This approach has received a considerable amount of attention in the literature (we refer the interested reader to, for example, Dolan (3) and Williams (4)). Our paper deals with this same problem with a different approach.

Another methodology to analyze efficiency and equity in health care allocation 
has been proposed by Clark (5). He examines how axiomatic bargaining theory can be used to suggest different rules to allocate resources among different patients. One of the main advantages of this approach is that it offers a unique solution, based on a set of conditions (axioms), to an allocation problem. Instead, in the SWF approach we only have a unique solution after we choose an inequality aversion parameter. The elicitation of this parameter might be problematic. There is a large evidence (6) that the general population has lots of problems to express their preferences about social issues in quantitative terms, as it is required by the empirical estimation of inequality aversion parameters. Apart from that, several SWF have been proposed in the health economics literature and the choice of the most appropriate functional form is far from being straightforward.

One of the important features of all the rules examined by Clark (5) is that the initial state of health of patients plays no role in the final way resources are distributed among them. This is so because the criteria examined in Clark (5) focus merely on the way health improvements are distributed among patients, irrespective of their initial health situations. This might be regarded as an undesirable characteristic of these solutions. In fact, some authors (7) have explained in detail why health improvements might not have the same social value irrespective of the initial health status. This literature seems to suggest that health improvements have more value if those who are severely ill receive them. This seems quite reasonable since improving the health of those who are worse off leads to more equality in the final distribution of health. If health is regarded as necessary to "flourish" as human being, then it is equality of the final stock of health of individuals what guarantees equal opportunities of achieving personal goals in life (see Culyer and Wagstaff (8)).

The first contribution of this paper is to add two new different solutions to Clark's in order to address the shortcoming mentioned above. These solutions are based on new developments in the theory of axiomatic bargaining. In particular, we follow the literature that adds to the previous framework the concept of claims (see Chun and Thomson (9) for a seminal reference). Although there is not a clear 
operational definition of what claims are in the theoretical literature, they can be thought of as reflecting ideal situations for all agents involved in the bargaining process. A typical example of claim problems is the so-called "bankruptcy problem": a firm goes bankrupt and its net worth is not enough to cover its debts to the creditors. How should this amount be divided among creditors who have different claims (amount of debt) over the totality of resources? The new solutions we consider take into account agents' claims in order to formulate rules to allocate resources. Since we study a problem with immediate policy implications, a key issue that cannot be avoided is the definition of what constitutes a claim, which will determine the distributive terms of the proposed solutions.

There is not a univocal definition of claims in the context of allocation of health care resources. In fact, this approach is compatible with several alternative definitions of claims. In this paper we use different definitions of claims for contexts in which we study resource allocation in health care. For instance, we could define the claim for a given individual as the stock of health to which everybody is entitled at birth. This idea is reminiscent of the "fair innings" concept, which in Williams (4) words "reflects the feeling that everybody is entitled to some "normal" span of health (usually expressed in life years)" [Williams (4), p. 117]. It could be thought as a reasonable expectation about a person's life health profile. In this sense, illness reduces the amount of health that a person is expected to have, creating a "gap" between this reasonable expectation (which defines the claim) and the amount of health that, due to illness, this person will finally enjoy. The existence of this health gap entitles the patient to receive services from the health system. This should not be understood as an absolute right to receive part of the health budget because it will also depend on the cost of treatment and the health gaps of the other patients. It should be noted that, in order to allocate resources, the concept of claims focuses on the health gap that an individual will suffer if no treatment is received and not on the health gains (number of QALYs gained) if treatment is received, although this does not mean that health gains are not taken into consideration. In our opinion, this is an important departure from other approaches to equity in health. Previous analyses 
(Wagstaff (2), Bleichrodt (10), Dolan (3)) have focused on how to distribute health improvements, while now we will focus on the health gap with respect to a predetermined final stock of health ("claim"). For this reason, the initial health state of the patient plays an important role in this model.

To clarify further, let us see a simple example. Assume that there are three patients $\mathrm{A}, \mathrm{B}$ and $\mathrm{C}$ aged 30, 40, and 50 respectively. Assume the three have a mortal illness and medical treatment can increase their life expectancy. The cost per year of life gained is, respectively, 3, 2, and 1 and the budget is 12 . Consequently, if we devoted all the money to only one of the three patients the number of years of life gained would be, respectively, 4, 6, and 12 . If we allocated resources according to health maximization, they should be entirely allocated to C. Alternatively, we could use an approach based on the concept of claims. Let us first define the claim that, for the sake of this example, will be established in 70 years (QALE at birth). Consequently, the three patients have a health gap because of illness of 40,30 and 20 QALYs. If resources are allocated according to their respective health gaps, then patient A should have priority over B, and B over C. However, we still need to decide how much more priority should A be given over B and C. This will be determined by the particular choices on equity taken by society. One of the main objectives of this paper is to present an analysis of such choices based on the concept of claims.

The second main contribution of the paper is to present the results from a survey in which we try to elicit what are the moral intuitions of society about these type of resource allocation problems and their solutions. Specifically, we present a problem of resource allocation with six possible solutions suggested by axiomatic bargaining theory. Four of those solutions coincide with Clark (5), while the other two are based on the concept of claims presented above. This survey methodology is inspired by previous work of Yaari and Bar-Hillel (11) and Bar-Hillel and Yaari (12). Interestingly, one of the conclusions we draw from this exercise is that solutions based on claims seem to have relatively strong support from our sample of 
respondents.

The rest of the paper is as follows. Section 2 and 3 present the model and resource allocation rules based on axiomatic bargaining theory without and with claims. Section 4 and 5 examines the main results from our survey. Section 6 concludes the paper and offers suggestions for further research.

\section{Bargaining problems: Some well-known solutions}

In this section we present Clark (5) model of resource allocation built upon axiomatic bargaining theory as the initial point of our argument. We briefly describe and characterize four well-known solutions of this model. These are the so-called Equal Increment (Egalitarian), Utilitarian, Nash, and Kalai-Smorodinsky solutions.

Let us assume that there are two patients (alternatively, groups of patients) $\mathrm{i}=1,2$. Health is measured in QALYs or in any other cardinal scale (e.g., for a patient who is suffering some permanent condition, the number of hours without pain she enjoys each day). For simplicity we shall use the expression 'units of health' when we refer to this measurement of the health status of the agents. We denote by s1 and $s_{2}$ the initial levels of health. The production function for the treatment of person $i$ is given by the concave, continuous function $f_{i}\left(H_{i}\right)$ [assume $f_{i}(0)=0$ ], where $H_{i}$ is the expenditure on health care for patient $i$. Thus, health of person i can be defined by the following expression: $h_{i}=S_{i}+f_{i}\left(H_{i}\right)$. Preferences of agent of type $i$ can be represented by a concave utility function $\mathrm{U}_{\mathrm{i}}\left(\mathrm{h}_{\mathrm{i}}\right)$. The health care budget to be allocated among patients is assumed to be $T<\infty$. We also assume that $f_{i}^{\prime}(T) \geq 0$ where $f_{i}^{\prime}$ is the first derivative of the production function for patient $i$.

In order to characterize the bargaining problem, we need to identify several elements. First, $d=\left(s_{1}, s_{2}\right)$, the initial endowment of health, is the disagreement point (or threat point) of the bargaining game. Patients are confined to this point if they 
cannot reach a unanimous agreement about the distribution of resources Second, we define the set of feasible health pairs, $\mathrm{P}$, given the initial health endowments, the production functions, and the total budget. Thus, $\mathrm{P}=\left\{\left(\mathrm{h}_{1}, \mathrm{~h}_{2}\right) \mid \mathrm{h}_{1} \geq \mathrm{s}_{1}, \mathrm{~h}_{2} \geq \mathrm{s}_{2}\right.$, $\left.\mathrm{T} \geq \mathrm{H}_{1}+\mathrm{H}_{2}\right\}$. Given finite $\mathrm{s}_{1}$, $\mathrm{s}_{2}$, and $\mathrm{T}$ and the concave and continuous production functions, the set $\mathrm{P}$ is compact and convex. Next, we define the bargaining problem as a pair $(P, d), d \in P$ and $P$ contains at least an element, $e=\left(h_{1}, h_{2}\right)$ which is strictly preferred by both patients to d. Finally, we define the constrained utopia point, $\mathrm{m}=\left(\mathrm{h}_{1}^{\mathrm{m}}, \mathrm{h}_{2}^{\mathrm{m}}\right)$, which is given by the maximum payoff enjoyed by each agent $\mathrm{i}$ given that the entire budget $T$ has been spent on treating her. Thus, $h_{i}^{m}=S_{i}+f_{i}(T)$. Obviously $\mathrm{m} \notin \mathrm{P}$. Formally, a solution to the game $(\mathrm{P}, \mathrm{d})$ can be defined as a function $\mathrm{g}(\mathrm{P}, \mathrm{d})$ which obtains a unique point in the feasible set $\mathrm{P}$ (thus, $\mathrm{g}_{\mathrm{i}}(\mathrm{P}, \mathrm{d})$ is the solution level of health of patient i). We first look at the solutions proposed in Clark (5).

\section{The Utilitarian solution}

The Utilitarian solution is the allocation that maximizes total health. Formally,

$$
\left(\mathrm{h}_{1}^{\mathrm{U}}, \mathrm{h}_{2}^{\mathrm{U}}\right)=\operatorname{argmax}\left\{\mathrm{h}_{1}+\mathrm{h}_{2} \mid\left(\mathrm{h}_{1}, \mathrm{~h}_{2}\right) \in \mathrm{P}\right\} .
$$

This is a well-known solution in the context of health economics. As it has been argued in the introduction, maximizing the total number of QALYs with a given budget has been the main distribution criterion used to allocate resources in health care in theory, although it has almost never been the dominant criterion for distributing resources in the real world. This is a solution basically focused on efficiency concerns (understanding efficiency as maximization of QALYs): the objective is to maximize the aggregate level of health of patients, measured on a cardinal scale (QALYs or any other possible metric). Figure 1 displays a graphical representation of this solution. The allocation depicted as point $\mathrm{U}$ maximizes total health from the use of a given amount of resources. 


\section{The Equal Increment (Egalitarian) solution}

This solution $\left(\mathrm{h}_{1}^{\mathrm{E}}, \mathrm{h}_{2}^{\mathrm{E}}\right)$ can be characterized as

$$
\mathrm{h}_{2}^{\mathrm{E}}-\mathrm{s}_{2}=\mathrm{h}_{1}^{\mathrm{E}}-\mathrm{s}_{1} \text {. }
$$

What this solution accomplishes is to allocate resources in such a way that the gains in health are the same for both patients. All patients will benefit the same from the common resources in terms of their health gains after the distribution of the budget. Point E in Figure 1 is the graphical representation of this solution.

\section{The Nash solution}

Nash (13) proposes the following solution:

$$
\left(\mathrm{h}_{1}^{\mathrm{N}}, \mathrm{h}_{2}^{\mathrm{N}}\right)=\operatorname{argmax}\left\{\left(\mathrm{h}_{1}-\mathrm{s}_{1}\right)\left(\mathrm{h}_{2}-\mathrm{s}_{2}\right) \mid\left(\mathrm{h}_{1}, \mathrm{~h}_{2}\right) \in \mathrm{P}\right\} .
$$

This solution allocates resources in a way that maximizes the product of health gains of both patients. Intuitively, this rule distributes resources such that any additional amount of money distributed would improve the health of each patient in exactly the same proportion. Of course, the final gains each patient get will depend on the particular treatment technology affecting each patient and the resources at hand, and, in this present context, is independent of the initial endowment of health of each patient. Point $\mathrm{N}$ in the production frontier in Figure 2 is the relevant allocation in this case.

\section{$\underline{\text { The Kalai-Smorodinsky solution }}$}

Kalai and Smorodinsky (14) propose a solution $\left(\mathrm{h}_{1}^{\mathrm{K}}, \mathrm{h}_{2}^{\mathrm{K}}\right)$ defined as 


$$
\left(\mathrm{h}_{2}^{\mathrm{K}}-\mathrm{s}_{2}\right) /\left(\mathrm{h}_{1}^{\mathrm{K}}-\mathrm{s}_{1}\right)=\left(\mathrm{h}_{2}^{\mathrm{m}}-\mathrm{s}_{2}\right) /\left(\mathrm{h}_{1}^{\mathrm{m}}-\mathrm{s}_{1}\right) .
$$

This solution allocates resources in such a way that the health gain of each patient is proportional to her ability to benefit from those resources. This ability is simply defined as the total health gain one could obtain if all resources were totally allocated to her. In other words, the final improvement in health must be proportional to the potential total improvement, given the disposable budget. The advocates of this solution regard the potential total improvements agents could get as "rough measures of the contributions of the respective agents to the cooperative endeavor and argue, perhaps, that if cooperation takes place then the solution should be the Pareto optimal allocation where the utilities of the different agents are proportional to $\left(\mathrm{h}_{1}^{\mathrm{m}}, \mathrm{h}_{2}^{\mathrm{m}}\right)$ " (Mas-Colell et al (15), p.844). Figure 1 (point $\mathrm{K}$ ) represents graphically this allocation.

An important common feature that all these solutions share, given the specification of the model, is that they allocate resources in a way which is completely independent of the initial health states, s1 and s2. Thus, health gains allocated to each patient are independent of the severity of the condition affecting them. The reason for this is that these solutions are basically focused on how the gains of health are distributed (in other words, the improvements in health enjoyed thanks to medical treatment, independently of her initial condition/state). In the next section we give some arguments trying to justify why this might be unreasonable in many contexts and explain new extensions within the axiomatic bargaining approach that propose solutions that are dependent of the initial levels of health.

\section{Bargaining problems with claims: New solutions}

We enrich the bargaining problem considered above by adding the concept of claims (as in Chun and Thomson (9)). This allows us to present and characterize two additional solutions to the allocation problem, which were not considered in Clark (7): the proportional and the equal loss solutions. This is by no means a trivial 
extension of the model in the sense that now we will be able to define new solutions that will specifically depend on the initial state of health of the individuals. As we shall see, these new solutions have intuitive appeal from a theoretical point of view, but more importantly, from an ethical point of view, in the sense that the results of our survey (details are available in the next section) show that a rather large part of the population we asked preferred allocations of resources which are based on this new formulation.

The first thing we need to do is to define a point representing the claims or expectations that agents might have before the start of the bargaining game about the way distribution of resources will take place, $\mathrm{c}=\left(\mathrm{c}_{1}, \mathrm{c}_{2}\right)$. This point is outside the feasible set, which simply means that claims are incompatible, $\mathrm{c} \notin \mathrm{P}$. The following lines present two different possible interpretations of claims in the context of the distribution of health care resources.

The first interpretation is to describe the claim as an exogenously determined amount of health to which everyone is entitled because there is a socio-political agreement about it. For instance, the claim could be fixed at 70 QALYs, if this is the (at birth) life expectancy adjusted for quality of the population.

The second interpretation, which we do not regard as contradictory with the first, is to fix the claim as the point up to which the marginal productivity of resources is positive $\left[c_{i}=\min h_{i}=S_{i}+f_{i}\left(M_{i}\right)\right.$ with $M_{i}$ such that $\left.f_{i}^{\prime}\left(M_{i}\right)=0\right]$. This coincides with the unconstrained utopia point in Clark (7). An example of this interpretation is straightforward: once a patient reaches a state of health characterized by 24 hours per day without pain, any additional amount of money devoted to treat her cannot increase her health (reduce hours of pain) any further. This maximum amount of money constitutes her claim. This particular interpretation of claims is not totally unfamiliar in the field of health economics, as it coincides with the definition of need "as expenditures required to exhaust capacity to benefit" advanced by Culyer and Wagstaff (8). Thus, in this particular case, our definition of health gap can be 
directly related with a standard definition of need in health economics and, consequently, the solutions we analyze are proposals to allocate resources based on such needs.

We define the bargaining problem with claims as a triple $(\mathrm{P}, \mathrm{d}, \mathrm{c})$ where $\mathrm{P}$ is compact and convex, $\mathrm{d} \in \mathrm{P}$ and $\mathrm{P}$ contains at least an element, $\mathrm{e}=\left(\mathrm{h}_{1}, \mathrm{~h}_{2}\right)$ which is strictly preferred by both patients to $\mathrm{d}$. A solution to the problem $(\mathrm{P}, \mathrm{d}, \mathrm{c})$ can be defined as a function $\mathrm{g}(\mathrm{P}, \mathrm{d}, \mathrm{c})$ which obtains a unique point in the feasible set $\mathrm{P}$ $\left(g_{i}(P, d, c)\right.$ is the solution level of health of patient $\left.i\right)$. We look at two of the solutions that have been, among others, proposed to solve this type of problems (See Chun and Thomson (9), Bossert (16) and Herrero and Marco (17) for details about this).

\section{The Proportional solution}

The proportional solutions is given by the expression:

$$
\left(\mathrm{h}_{2}^{\mathrm{P}}-\mathrm{s}_{2}\right) /\left(\mathrm{h}_{1}^{\mathrm{P}}-\mathrm{s}_{1}\right)=\left(\mathrm{c}_{2}-\mathrm{s}_{2}\right) /\left(\mathrm{c}_{1}-\mathrm{s}_{1}\right)
$$

The proportional solution gives patients resources to improve their health states in a way that is proportional to their unsatisfied claims (which also could be interpreted as their respective "needs"). Clearly now the solution will depend on the situation of the disagreement point, that is, $s_{1}$ and $s_{2}$ (initial states of health). This is a solution that has been justified as a reasonable way of allocating resources at least since the works of Aristotle on justice. Figure 3 (point $\mathrm{P}$ ) shows the graphical representation of this allocation.

\section{$\underline{\text { The Equal Loss solution }}$}

We characterize this solution as follows: 
$\left(\mathrm{h}_{1}^{\mathrm{EL}}, \mathrm{h}_{2}^{\mathrm{EL}}\right)=\left(\mathrm{l}_{1}, \mathrm{l}_{2}\right)$ such that $\mathrm{c}_{2}-1_{2}=\mathrm{c}_{1}-1_{1}$ if $1_{\mathrm{i}} \geq \mathrm{s}_{\mathrm{i}}$; if $\mathrm{l}_{\mathrm{i}}<\mathrm{s}_{\mathrm{i}}$, the solution is given by $\mathrm{h}_{\mathrm{i}}^{\mathrm{L}}$ : and $\mathrm{h}_{\mathrm{j}}^{\mathrm{L}}=\mathrm{h}_{\mathrm{j}}^{\mathrm{m}}, \mathrm{i} \neq \mathrm{j}$.

This solution allocates resources in a way such that the difference between claims and final states of health is exactly the same for each patient. Here we restrict the solution [Bossert (1993)] in such a way that no patient can be given negative amounts of health improvement. This means that no agent can have a final state of health lower than her initial state (this is to guarantee that individual rationality holds: nobody would engage in bargaining to end up in a worse position than at the beginning). If claims are identical for all individuals, this solution tends to equalize the final state of health of each patient and so it could be considered an "outcome egalitarian" solution. This solution is related to Rawls' theory of justice, in the sense that in general will coincide with the criterion of the "maximin". It can also be linked to Culyer and Wagstaff (8) main proposal: "a just distribution of health is an equal distribution" (p. 452). Figure 3 (point EL) represents this allocation in a graphic.

\section{A survey on justice judgments}

We turn now to the problem of finding out whether the solutions presented in the previous sections are coincident with the opinions the general population may have about fairness in resource allocation in health care. In order to do this, we surveyed 2010 students of two Spanish universities (University of Murcia and Univertitat Pompeu Fabra at Barcelona) using a similar methodological framework as Yaari and Bar-Hillel (11) in their seminal paper about experimental approaches to justice. We elaborated several examples in which resources had to be distributed between two patients. Following the theoretical framework already exposed, six potential resource allocations were given and respondents were asked to choose among them using the perspective of an impartial judge who must choose the best solution. This survey had two main objectives. First, we wanted to test whether today most widely used solution to health allocation problems, namely the 
utilitarian-health maximization, was actually the most supported. The second was to test for the approval of the two solutions based on the concept of claims introduced in the paper.

We elaborated a wide range of cases to test the acceptance of each of the six solutions in different contexts and under different circumstances. More specifically, we wanted to test whether the number of people favoring each solution was different when a) the general context of the decision was different; b) the capacity to benefit from health care between the two patients changed; and c) the health gap of patients also varied. A different level of at least one of these attributes then characterized each case: context, capacity to benefit, and health gap.

We set our problem in two different contexts characterized by two different health conditions. The first was a potentially mortal illness and the second a mild health problem that, if not treated, produced one day of pain. In the first case, the treatment increased life expectancy and in the second reduced the number of hours of pain. In both cases there were not enough resources to ensure an optimal health state for the two patients. Thus, the more resources were used to treat a patient, the worse off the other patient would end up.

We constructed the examples in such a way that health was a variable that monotonically and continually increased with the amount of resources devoted to each patient. However, the treatment did not have the same effect for both patients. Consequently, in order to reach a certain health improvement, one patient needed more resources than the other did or, as we have said above, both patients did not have the same capacity to benefit from health care. We used three different levels of relative capacity to benefit: one patient was twice (five times) (ten times) as capable as the other was.

Different levels of relative need (health gaps) were also analyzed. In the context of hours of pain, the health gap is the amount of hours of pain (between 
zero and 24) that each patient suffers without treatment. This is so because we are assuming that they both have a claim of 24 hours without pain. The case of years of life is more problematic because it is not so clear what is the claim in terms of years of life. We decided to tell the respondents that they had to consider 80 years as the usual life expectancy. The health gap is defined in this case as the distance between age of death without treatment and the claim (80 years). We used three different levels of need in each context. In the context of years of life the two patients without treatment could die at 20,40 or 60 , so that the health gaps were then 60,40 and 20. In the context of hours of pain the two patients without treatment could have 24,18 or 12 hours with pain and the health gaps coincided with these same amounts. There were nine potential combinations of levels of need in both contexts.

The number of potential cases to analyze was $54(2 \times 3 \times 9)$. Only two cases were excluded because they had almost trivial solutions, so we were left with 52 cases (see appendices). Respondents were placed in a hypothetical situation in which they had to split a certain budget between two patients. For each case, we computed six allocations of resources corresponding to the six solutions already mentioned and asked the respondents to choose the allocation they thought was the best. Each subject was given two cases, one of each context, to "solve". To avoid problems of people anchoring always in the same solution for each of the two contexts, the other two parameters (capacity to benefit and health gaps) were different in each case. We surveyed 27 groups of students for a total of 2010 individuals. Although the number of students in each group was different, almost all groups had more than 70 students.

\section{$\underline{\text { Results }}$}

The results of the survey for the 52 cases studied are shown in appendix 3 .

The following lines present the results that are more relevant concerning the two 
main objectives of the study, that is, the evaluation of the solutions based on claims and the utilitarian solution.

1. Solutions based on claims

\section{TABLES 1 AND 2}

In table 1 we grouped the data for the Equal Loss and the Proportional solutions in nine blocks depending on the relative capacity to benefit and the relation between health gap and capacity to benefit. For example, when patient A needs 1 million to gain 1 year of life and patient B only 0.2 (difference in capacity to benefit 1 to 5) we have three blocks: a) the two patients have the same health gap (same age in the case of years of life); b) the younger (larger health gap) patient has less capacity to benefit; and c) the younger patient has more capacity to benefit. The main reason to proceed this way was that in some cases the two solutions coincided with other solutions and, then, we could not know which one was in fact being favored. We dealt with this problem in the following way. For the equal health gap case, we just present the aggregate data for the Equal Loss, Equal Increment, and Proportional solutions because they always coincide. For the rest of cases we aggregate the data only for those cases in which the solutions do not coincide with any other.

Looking at table 1 we observe that there is a large variation in the number of people choosing the solutions based on claims. We emphasize the following general trends.

a) The solutions based on claims are more favored in the context of hours of pain than in the context of life years. The context, then, is influencing the attractiveness of the solutions. 
b) Cases of equal health gap. In these cases, the solutions EL, P and EI coincide and are the most preferred. At the same time, the percentage of people choosing this option decreases when the difference in capacity to benefit increases. This seems rather natural given that this allocation gives priority to equality and has the largest cost in terms of loss of aggregate health. The bigger is the difference in the relative capacity to benefit of both patients, the larger is the aggregate health that has to be lost to achieve perfect equality in the distribution of health. However, even taking this into account, it seems that we can say that, when patients have the same health gap, the most favored decision is to split resources such that both patients receive the same health increment and then end up in the same final situation.

c) Cases where the patient with the largest health gap has less capacity to benefit. The $\mathrm{P}$ solution is chosen by approximately $25 \%$ of people in this case, both in the context of years and in the context of hours. The EL is chosen by a reduced number of people in the context of years. The explanation of this lack of attractiveness of the EL solution for this case is due, in our opinion, to what we can call the "zero effect" (a kind of framing effect). The problem with the EL solution in this case is that, in almost all cases, the implementation of this principle implies devoting all resources to the patient with largest health gap to allow him to reach the same level of health than the other patient. Because of this, we cannot be sure whether the EL solution is not acceptable because of its intrinsic features or because, in the cases studied, it required giving all resources to one patient.

In the case of hours of pain the attractiveness of the EL solution is clearly greater. Here the "zero effect" also has some influence on the results. In the case in which the patient with the largest health gap has less capacity to benefit, the EL is preferred on average by $32 \%$ of respondents. However, if we distinguish between the cases in which the EL solution implies to give everything to the patient with the largest health gap (cases 12 and 15 to 18) and the cases in which the equal loss solution does not imply giving nothing to someone (cases 10, 11, 13 
and 14), we find that the support for this solution is respectively, $20 \%$ and $45 \%$.

In summary, we can draw two main conclusions from all this. First, when the EL solution is not influenced by the "zero effect", the number of people choosing solutions based on claims is larger than $50 \%$. The concept of claims is important when the patient with the largest health gap has less capacity to benefit and mainly in the context of hours. The second is that people apply simple equity rules like "you should not give everything to one person", although its rationality is not clear, at least in the framework we study in this paper.

d) Cases where the patient with the largest health gap has more capacity to benefit. The only clear tendency in these cases is that almost nobody chose the $\mathrm{P}$ solution, both in the case of years and in the case of hours. The EL solution is chosen, on average, by $30 \%$ of the respondents in the context of the life threatening disease and by $40 \%$ in the context of hours. In summary, when the patient with the largest health gap has more capacity to benefit, it seems that the only clear message of the data is that the P solution is not chosen and that the EL solution receives a relatively important support.

2. The utilitarian (health maximization) solution

Is health maximization a solution that fits the moral intuitions of our respondents? To answer to this question we must calculate the support this solution receives (table 2). As before, we have the problem that the solution coincides with other solutions in some cases. We then present the results for the cases in which this is not so.

\section{TABLE 2}

From these data we can conclude that the utilitarian solution is not very favored among our respondents. Given that this solution has also the feature that, in some occasions, it requires giving everything to the patient with the largest 
capacity to benefit, we tried to see the influence of the "zero effect". In the context of a life threatening disease, we found that for those cases in which the utilitarian solution was influenced by the "zero effect" the percentage of people choosing it was $2,5 \%$ and in the rest of cases it was $16 \%$. However, in the context of hours for both kind of cases (with zero and no-zero effect) the percentage of support for the utilitarian solution was about $8 \%$. This seems to suggest that the attractiveness of the utilitarian solution is low even when the influence of the "zero-effect" is low.

\section{Other solutions}

As for the rest of solutions (data shown in appendix 3) the general conclusions that can be drawn from our survey are that they are not as widely chosen as the solutions based on claims but they are much more preferred than the utilitarian solution by our respondents.

The Equal Increment solution seems to be especially attractive when the patient with the largest health gap has less capacity to benefit. In our opinion, this is due to the fact that in this case in order to give the same amount of life years to both people we need to give more money to the worse-off individuals. Then the solution has two attractive features, namely, justice as equality of something (the increment of years of life) and a more favorable distribution of resources for the worst off. When the patient with the largest health gap has more capacity to benefit to implement the E solution amounts to giving more resources to the patient with the lowest health gap and this makes the solution unattractive. The Nash and the Kalai Smorodonsky solutions are specially favored in the opposite case to the EI solution, that is, they are more preferred when the patient with the largest health gap has more capacity to benefit.

What can we conclude from these data? 
1. There is not a clear dominant principle to solve our problem. Depending on the differences in capacity to benefit, health gap and context, some solutions are better accepted than others. For example, when the two patients have the same health gap subjects clearly favor to distribute resource in a way that is inversely proportional to cost, achieving equality in the health increments and equality in the final distributions of health. The EL, P and E are then favored. Resource allocation in the health sector has a varied casuistic and it is difficult to find a unique principle which is always the most preferred.

2. The EL solution is chosen frequently. We would say that on average is the most preferred solution, although we cannot say it is always the most preferred solution. If we forget about the cases where this solution is influenced by the "zero effect", the EL solution always receives at least $30 \%$ of the stated preferences. There is no other solution with such support. This provides some support to equality of health as the leading objective in the allocation of health care resources.

3. The concept of claims is important and the solutions based on it receive considerable support in our study. In fact, when we add the votes of the two solutions derived from concept of claim, they amount to approximately $40 \%$ of votes on average. It seems to us that this concept and its implications deserve more research in the studies of equity in the health care sector.

4. Solutions based on claims receive more support in the context of hours than in the context of years of life. This seems to contradict Williams' fair innings argument. Williams' claim is that people are entitled to the same amount of healthy years. However, our research shows that people care less about this than about an equal treatment in terms of number of hours. That is, people seem to care only about equality of health regardless of what people have already received or will still receive (hours are such a tiny fraction of total duration that we might ignore it). Our results suggest that people favor an equal distribution of health independently of its contribution to an equal distribution of the stock of health that 
people enjoys during their life.

5. The health maximization solution does not have a very strong support in the cases we have studied.

6. Framing effects like the "zero effect" can highly influence perceptions of justice. There are some solutions that more "easily" attract attention from the respondents. For example, Equal Loss and Equal Increment, because they are somehow symmetric (identical final health state, identical health increment). Results of this kind of surveys may reflect true preferences as well as framing effects.

\section{A second survey}

In our first survey, we clearly used a method that prioritized the quantity of information over qualitative aspects. This is because we interviewed a lot of people were not necessarily familiar with the kind of questions we asked. We cannot sure about whether we elicited well-constructed preferences. Certainly, the high number of people surveyed was very useful to provide some general ideas about the importance of the different principles analyzed but what would have happened if we had had time to explain our subjects the principles that originated the numbers? Would they have given the same answer? We had the opportunity to approach this question.

A group of 67 students of Politics followed a course on Public Economics and they received lessons on equity and allocation of public resources. They received four hours of teaching about solutions to resource allocation problems based on axiomatic bargaining. Before they started the sessions, they were given three of the above cases and were asked to choose among the six solutions for each of the three cases. After the sessions about equity and axiomatic bargaining they were asked to do some practical exercises. They had to solve problems of resource 
allocation using the six solutions. The problems encompassed different areas of public sector decision making and, among them, there were the three cases they had been asked to solve before the start of the sessions. Thus, they could see the relation between principles and numbers. We then asked them two questions. The first was which of the six solutions they thought it was the best as general principle of social decision-making. The second was to ask them to choose again the best solution in each of the three cases. The principles that originated the numbers were identified, that is, they received a paper where the numbers were related to the different solutions. Consequently, we had the following information from the subjects: a) the choice they took before they knew the theory, b) the solution they favored as a general principle of social choice c) the choice they made after knowing the theory behind the numbers. Results for this exercise are shown in table 3 .

\section{TABLE 3}

We can see that after the theoretical explanation the students considered that the two solutions based on the concept of claim were the best principles of social choice (we are well aware that this can be due simply to the fact that they way they were taught influenced their choices). We can also see that the choices after the theoretical explanation also changed and more people chose the two solutions based on claims. However, when they faced the practical exercises they did not automatically chose the solution that they had favored in theory. Even when they understood where the numbers came from, even after knowing which solution was behind each number, a lot of them chose a solution they had not chosen as the best in theory. This apparent lack of consistency surprised us and we interviewed around 20 students individually about it. They justified this choice by saying something like "although I think this solution is the best in theoretical terms, given the numbers of this case I would choose a different one in this occasion". This seems to justify the impression that what people considers fair or unfair greatly depends on specific features of the case and this reinforces the idea that is difficult 
to reach an agreement about general principles that can be applied and accepted by society in all cases.

\section{Conclusions}

The objective of this paper has been to analyze principles of resource allocation which explicitly take equity issues into account. More specifically, we have shown how principles based on axiomatic bargaining with claims lead to distributions of resources different from standard health maximization criteria. These principles base the distribution of health care on what we called "health gap", that is, the distance of the current health situation of patients to a certain "ideal" point (or claim). This certainly introduces a different way of looking at equity issues. In order to illustrate this approach, we would like to show how it tackles ethical objections that have been raised against standard health maximization. For instance, one of these objections, which led to the rejection of CEA in Oregon, (18) was that it discriminates against the disabled. This criticism has also been raised by Anand and Hanson (19) against DALYs. In the traditional Cost-Utility Analysis (CUA), disabled people might receive lower priority because of their lower capacity to benefit from health expenditures. This is not the case in our approach here because what determines the resource allocation is the right to a particular stock of health. For example, let us assume that on average QALYs expectancy at birth is 70 and that somebody has been living in a wheel chair (with quality of life equal to 0.5 ) from birth. She is now 40 and has a mortal illness. Treatment will extend life expectancy in 20 years in the wheel chair. Imagine that somebody else is 40 years old and is in the same situation. Treatment will also increase life expectancy in 20 years but in good health. In other approaches, the allocation of resources is a function of the amount of QALYs they can produce, that is, 10 and 20. Using the concept of claims we do not focus on these numbers. The key figures here are the differences with respect with the indicative stock of health that both patients have. The first patient, dying at 40 will have received 20 QALYs along her life and, then, the gap will be of 50 QALYs with respect to the claim of 
70. The second patient, dying at 40 loses 30 QALYs. In this case, the handicapped patient has a larger entitlement to health care resources than the other patient does.

Another illustration of how the ideas presented in this paper can contribute to the theoretical debate on equity is to compare this approach with the approach taken by Dolan (1998). He understands that equity may imply that similar health increments may have different social value when initial situations are different. Using data from a small sample he concludes that a health improvement from 0.2 to 0.4 (in the standard scale from 0 to 1 ) has the same social value than a health improvement from 0.4 to 0.8 . The influence of equity here is reflected in the fact that improvements affecting a patient who is in a worse initial situation (0.2) than another (0.4) have greater value from a social viewpoint. This is not the concept of equity that the idea of claim encapsulates. Its introduction allows us to consider another element in the problem, namely, the ideal situation (claim) of each patient. In order to illustrate this argument, let us introduce the following example: suppose the patient in 0.2 is ninety years old and the patient in 0.4 is 20 years old. It is not clear now that equity requires giving priority to the patient in 0.2 . Let us assume that for the 90 years old the health state that he/she can reasonably expect is 0.6 , while the 20 years old can expect to have perfect health (1.0). The health gap is then 0.4 for the first patient and of 0.6 for the second. It is not clear now that the 90 years old is in a worse health condition than the 20 years old. In fact, our approach would say the opposite.

Given that the two solutions based on claims generally lead to different resource allocation decisions than other principles, we have tried to study whether they gather relevant social acceptability. To explore this, we have undertaken two empirical studies aimed at measuring the degree of social support of the different principles based on axiomatic bargaining. An obvious limitation of this exercise is that our sample is not representative of the general population. For this reason, the results should be handled with care. Nevertheless, we believe that our survey strongly suggests that it could be worth undertaking a similar exercise with a larger 
and more representative sample.

Our paper has several limitations that we would like to comment. First, there are a number of theories of equity in health which are not presented in this paper (e.g. 20, 21, 22). They also provide arguments to choose among different resource allocations. Nonetheless, we restricted ourselves to theories based on axiomatic bargaining. One obvious reason for this is simply that we cannot include all theories in the same study. A second reason is that some of these theories do not provide clear solutions to the allocation problems we used. For example, we do not know what kind of resource allocation is implied by the concept of Daniels' decent minimum health in the cases we studied. Surely, the theory is interesting enough as a theory of justice but it is far from clear what it implies for the cases we studied. The same happens with other theories of justice: an effort ought to be made to be more specific about their specific policy implications. We consider this a very interesting research area which, nevertheless, greatly exceeds the possibilities of this paper.

A second limitation is that the bargaining solutions presented in the paper assume the same consequentialist approach that is implied in the SWF approach or in Welfare Economics in general. None of the bargaining solutions presented in this paper rules out certain outcomes purely because reaching them requires unethical actions or processes, such as right violations. Modern political philosophers like Rawls or Nozick take a very different position. They adopt an approach based on fundamental rights very different from our approach which is based on final allocation outcomes. We should be aware that some of the solutions devised by axiomatic bargaining (or by the SWF approach) can be unfeasible in practice because they imply some rights violation. However, as it has been explained above, the concept of claims can be used sometimes to overcome some rights violations (e.g. discrimination against the disabled) presented in traditional CEA. 
Nevertheless, we think that we have shown that the theoretical ideas presented in the paper allow us to deal with equity issues in a reasonable way, so that this approach deserves further investigation. Several studies could be conducted as a follow-up to this one. One would be to organize some focus groups to explain the concept of claims and to test the support it receives from the general population. Another which could be related to the first, would consist in choosing more realistic cases (medical treatments) and see whether the solutions based on claims are accepted. For instance, we are now involved in a study about priority principles for kidney transplants where social support for solutions based on claims could be tested. In a more general sense, we believe the results from our surveys are interesting enough to justify future surveys with more realistic scenarios and with representative samples of the population. 


\section{References}

1. Olsen, J. A. "Theories of justice and their implications for priority setting in health care" Journal of Health Economics , 1997; 16(6): 625-641

2. Wagstaff, A. "QALYs and the equity-efficiency trade-off" Journal of Health Economics, 1991; 10(1): 21-41.

3. Dolan, P. "The measurement of individual utility and social welfare" Journal of Health Economics, 1998; 17(1): 39-52.

4. Williams, A. "Intergenerational equity: an exploration into the 'Fair Innings' argument" Health Economics, 1997; 6: 117-132

5. Clark D. "Priority setting in health care: An axiomatic bargaining approach" Journal of Health Economics, 1995: 14: 345-360.

6. Kahneman, D. Paul Slovic, Amos Tversky Judgment under uncertainty: heuristics and biases, Cambridge University Press 1988

7. Nord, E. Cost-value analysis in health care, Cambridge University Press, 1999.

8. Culyer, A.J. and Wagstaff, A. "Equity and equality in health and health care" Journal of Health Economics, 1993; 12: 431-457.

9. Chun, Y. and Thomson, W. "Bargaining problems with claims" Mathematical Social Sciences, 1992; 24: 19-33.

10. Bleichrodt, Han Health Utility Indices and Equity Considerations, Journal of Health Economics 1997; 16(1): 65-91.

11.Yaari, M. and Bar-Hillel, M. "On dividing justly" Social Choice and Welfare, $1984 ; 1: 1-24$.

12. Bar-Hillel, M. and Yaari, M. "Judgments of distributive justice" in Mellers, B.A. and Baron, J. (eds.) Psychological perspectives on justice: theory and applications Cambridge University Press, 1993.

13. Nash, J. The bargaining problem, Econometrica, 1950; 28:155-162.

14. Kalai, E. and Smorodinsky, M. Other solutions to Nash's bargaining problem, Econometrica, 1975; 43:513-518.

15. Mas-Colell, A., Whinston, M.D. and Green, J.R. Microeconomic Theory Oxford University Press, 1995. 
16. Bossert W. "An alternative solution to bargaining problems with claims" Mathematical Social Sciences, 1993; 25: 205-220

17. Herrero, C. and M.C. Marco "Rational equal-loss solutions for bargaining problems" Mathematical Social Sciences, 1993; 26: 273-284.

18. Sullivan. LW Letter to Gov. Barbara Roberts. Department of Health and Human Services, 1992.

19. Anand, S. and Hanson, K. "Disability-adjusted life years: a critical review" Journal of Health Economics , 1997; 16(6): 685-702.

20. Daniels, N. Just health care, Cambridge University Press, 1985.

21. Dworkin, R. "What is equality? Part 1: Equality of Welfare", Philosophy \& Public Affairs, 1981; 10 (3): 185-246.

22. Dworkin, R. "What is equality? Part 2: Equality of Resources", Philosophy \& Public Affairs, 1981; 10 (4): 283-345. 
Appendix 1. Cases studied in the survey.

\section{YEARS}

\begin{tabular}{|c|c|c|c|c|c|c|c|c|c|c|c|c|c|c|}
\hline \multirow{4}{*}{$\begin{array}{l}\text { Patient } \\
\text { Age } \\
\text { Cost/year }\end{array}$} & \multicolumn{2}{|c|}{ Case 1} & \multicolumn{2}{|c|}{ Case 2} & \multicolumn{2}{|c|}{ Case 3} & \multicolumn{2}{|c|}{ Case 4} & \multicolumn{2}{|c|}{ Case 5} & \multicolumn{2}{|c|}{ Case 6} & \multicolumn{2}{|c|}{ Case 7} \\
\hline & A & $\mathrm{B}$ & A & $\mathrm{B}$ & $\mathrm{A}$ & B & A & $\mathrm{B}$ & A & $\mathrm{B}$ & A & $\mathrm{B}$ & A & $\mathrm{B}$ \\
\hline & 20 & 20 & 40 & 40 & 60 & 60 & 20 & 20 & 40 & 40 & 20 & 20 & 40 & 40 \\
\hline & 1 & 0,5 & 1 & 0,5 & 1 & 0,5 & 1 & 0,2 & 1 & 0,2 & 2 & 0,2 & 2 & 0,2 \\
\hline & \multicolumn{2}{|c|}{$\Delta$ Years } & \multicolumn{2}{|c|}{$\Delta$ Years } & \multicolumn{2}{|c|}{$\Delta$ Years } & \multicolumn{2}{|c|}{$\Delta$ Years } & \multicolumn{2}{|c|}{$\Delta$ Years } & \multicolumn{2}{|c|}{$\Delta$ Years } & \multicolumn{2}{|c|}{$\Delta$ years } \\
\hline $\mathrm{EI}$ & $13,3^{*}$ & $13,3^{*}$ & $13,3^{*}$ & $\begin{array}{l}13,3 \\
*\end{array}$ & $6,66^{*}$ & $6,66^{*}$ & $16,6^{*}$ & $16,6^{*}$ & $16,6^{*}$ & $16,6^{*}$ & $9,1^{*}$ & $9,1^{*}$ & $9,1^{*}$ & $9,1^{*}$ \\
\hline EL & $*$ & * & $*$ & $*$ & * & * & * & $*$ & * & * & * & $*$ & * & * \\
\hline $\mathrm{P}$ & * & * & * & $*$ & * & $*$ & * & * & * & * & * & $*$ & * & * \\
\hline $\mathrm{U}$ & 0 & 40 & 0 & 40 & 0 & 20 & 8 & 60 & $12 \#$ & $40 \#$ & 4 & 60 & $6 \#$ & $40 \#$ \\
\hline $\mathrm{N}$ & $10 \#$ & $20 \#$ & $10 \#$ & $20 \#$ & $5 \#$ & $10 \#$ & 10 & 50 & $\#$ & $\#$ & 5 & 50 & \# & \# \\
\hline K-S & $\#$ & \# & $\#$ & \# & $\#$ & \# & 12,5 & 37,5 & 14,3 & 28,6 & 6,3 & 37,5 & 7,1 & 28,6 \\
\hline
\end{tabular}

The * and the \# symbols indicate solutions that coincide in a certain case

\begin{tabular}{|c|c|c|c|c|c|c|c|c|c|c|c|c|c|c|}
\hline \multirow{4}{*}{$\begin{array}{l}\text { Patient } \\
\text { Age } \\
\text { Cost/year }\end{array}$} & \multicolumn{2}{|c|}{ Case 8} & \multicolumn{2}{|c|}{ Case 9} & \multicolumn{2}{|c|}{ Case 10} & \multicolumn{2}{|c|}{ Case 11} & \multicolumn{2}{|c|}{ Case 12} & \multicolumn{2}{|c|}{ Case 13} & \multicolumn{2}{|c|}{ Case 14} \\
\hline & $\mathrm{A}$ & $\mathrm{B}$ & A & $\mathrm{B}$ & A & $\mathrm{B}$ & A & B & A & $\mathrm{B}$ & A & B & A & B \\
\hline & 20 & 40 & 40 & 60 & 20 & 60 & 20 & 40 & 40 & 60 & 20 & 60 & 20 & 40 \\
\hline & 1 & 0,5 & 1 & 0,5 & 1 & 0,5 & 1 & 0,2 & 1 & 0,2 & 1 & 0,2 & 2 & 0,2 \\
\hline & \multicolumn{2}{|c|}{$\Delta$ Years } & \multicolumn{2}{|c|}{$\Delta$ Years } & \multicolumn{2}{|c|}{$\Delta$ Years } & \multicolumn{2}{|c|}{$\Delta$ Years } & \multicolumn{2}{|c|}{$\Delta$ Years } & \multicolumn{2}{|c|}{$\Delta$ Years } & \multicolumn{2}{|c|}{$\Delta$ years } \\
\hline EI & \begin{tabular}{|l}
13,3 \\
\end{tabular} & 13,3 & $13,3^{*}$ & $\begin{array}{l}13,3 \\
*\end{array}$ & $13,3^{*}$ & $\begin{array}{l}13,3 \\
*\end{array}$ & 16,6 & 16,6 & $16,6^{*}$ & $16,6^{*}$ & $16,6^{*}$ & $16,6^{*}$ & 9,1 & 9,1 \\
\hline EL & 20 & 0 & 20 & 0 & 20 & 0 & 20 & 0 & 20 & 0 & 20 & 0 & 10 & 0 \\
\hline $\mathrm{P}$ & 15 & 10 & 16 & 8 & 17,1 & 5,7 & 17,6 & 12 & 18,2 & 9,1 & 18,74 & 6,3 & 9,4 & 6,3 \\
\hline $\mathrm{U}$ & 0 & 40 & $10 \#$ & $20 \#$ & $10 \#$ & $20 \#$ & $12 \#$ & $40 \#$ & $16 \#$ & $20 \#$ & $16 \#$ & $20 \#$ & 6 & 40 \\
\hline $\mathrm{N}$ & $10^{*}$ & $20 *$ & $\#$ & $\#$ & $\#$ & $\#$ & $\#$ & $\#$ & $\#$ & $\#$ & $\#$ & $\#$ & 6,5 & 35 \\
\hline $\mathrm{K}-\mathrm{S}$ & * & $*$ & * & $*$ & $*$ & $*$ & 14,3 & 28,6 & $*$ & $*$ & $*$ & $*$ & 7,1 & 28,6 \\
\hline
\end{tabular}

\begin{tabular}{|c|c|c|c|c|c|c|c|c|c|c|c|c|c|c|}
\hline \multirow{4}{*}{$\begin{array}{l}\text { Patient } \\
\text { Age } \\
\text { Cost/year }\end{array}$} & \multicolumn{2}{|c|}{ Case 15} & \multicolumn{2}{|c|}{ Case 16} & \multicolumn{2}{|c|}{ Case 17} & \multicolumn{2}{|c|}{ Case 18} & \multicolumn{2}{|c|}{ Case 19} & \multicolumn{2}{|c|}{ Case 20} & \multicolumn{2}{|c|}{ Case 21} \\
\hline & A & B & A & $\mathrm{B}$ & A & B & A & B & A & B & A & B & A & B \\
\hline & 40 & 60 & 20 & 60 & 60 & 20 & 40 & 20 & 60 & 40 & 60 & 20 & 40 & 20 \\
\hline & 2 & 0,2 & 2 & 0,2 & 1 & 0,5 & 1 & 0,5 & 1 & 0,5 & 1 & 0,2 & 1 & 0,2 \\
\hline & \multicolumn{2}{|c|}{$\Delta$ Years } & \multicolumn{2}{|c|}{$\Delta$ Years } & \multicolumn{2}{|c|}{$\Delta$ Years } & \multicolumn{2}{|c|}{$\Delta$ Years } & \multicolumn{2}{|c|}{$\Delta$ Years } & \multicolumn{2}{|c|}{$\Delta$ Years } & \multicolumn{2}{|c|}{$\Delta$ Years } \\
\hline$\overline{E I}$ & 9,1 & 9,1 & 9,1 & 9,1 & 13,3 & 13,3 & 13,3 & 13,3 & 13,3 & 13,3 & 16,6 & 16,6 & 16,6 & 16,6 \\
\hline EL & 10 & 0 & 10 & 0 & $0 *$ & $40 *$ & 6,6 & 26,6 & 6,6 & 26,6 & $10 *$ & $50^{*}$ & 13,3 & 33,3 \\
\hline $\mathrm{P}$ & 9,5 & 4,8 & 9,68 & 3,2 & 8 & 24 & 11,4 & 17,1 & $10^{*}$ & $20^{*}$ & $12,5 \#$ & $37,5 \#$ & 15,4 & 23 \\
\hline $\mathrm{U}$ & $8^{*}$ & $20^{*}$ & $8 *$ & $20^{*}$ & $*$ & $*$ & 0 & 40 & 0 & 40 & 8 & 60 & 8 & 60 \\
\hline $\mathrm{N}$ & $*$ & $*$ & * & $*$ & $10 \#$ & $20 \#$ & $10 \#$ & $20 \#$ & $*$ & $*$ & $*$ & * & 10 & 50 \\
\hline $\mathrm{K}-\mathrm{S}$ & 8,3 & 16,7 & 8,3 & 16,7 & $\#$ & $\#$ & $\#$ & $\#$ & $*$ & $*$ & $\#$ & $\#$ & 12 & 37,5 \\
\hline
\end{tabular}




\begin{tabular}{|c|c|c|c|c|c|c|c|c|}
\hline \multirow{4}{*}{$\begin{array}{l}\text { Patient } \\
\text { Age } \\
\text { Cost/year }\end{array}$} & \multicolumn{2}{|c|}{ Case 22} & \multicolumn{2}{|c|}{ Case 23} & \multicolumn{2}{|c|}{ Case 24} & \multicolumn{2}{|c|}{ Case 25} \\
\hline & A & B & A & B & A & B & A & B \\
\hline & 60 & 40 & 60 & 20 & 40 & 20 & 60 & 40 \\
\hline & 1 & 0,2 & 2 & 0,2 & 2 & 0,2 & 2 & 0,2 \\
\hline & \multicolumn{2}{|c|}{$\Delta$ Years } & \multicolumn{2}{|c|}{$\Delta$ Years } & \multicolumn{2}{|c|}{$\Delta$ Years } & \multicolumn{2}{|c|}{$\Delta$ Years } \\
\hline $\mathrm{EI}$ & 16,6 & 16,6 & 9,1 & 9,1 & 9,1 & 9,1 & 9,1 & 9,1 \\
\hline EL & 13,3 & 33,3 & 5,5 & 45,5 & 7,3 & 27,3 & 7,3 & 27,3 \\
\hline $\mathrm{P}$ & $14,3 \#$ & $28,6 \#$ & 7,7 & 23 & 8,7 & 13 & 8,3 & 16,7 \\
\hline $\mathrm{U}$ & $12 *$ & $40^{*}$ & 4 & 60 & 4 & 60 & $6^{*}$ & $40^{*}$ \\
\hline $\mathrm{N}$ & * & $*$ & 5 & 50 & 5 & 50 & $*$ & $*$ \\
\hline K-S & $\#$ & $\#$ & 6,3 & 37,5 & 6,3 & 37,5 & 7,1 & 28,5 \\
\hline
\end{tabular}

HOURS

\begin{tabular}{|c|c|c|c|c|c|c|c|c|c|c|c|c|c|c|}
\hline \multirow{4}{*}{$\begin{array}{l}\text { Patient } \\
\text { Hours } \\
\text { without } \\
\text { pain } \\
\text { Cost/hour }\end{array}$} & \multicolumn{2}{|c|}{ Case 1} & \multicolumn{2}{|c|}{ Case 2} & \multicolumn{2}{|c|}{ Case 3} & \multicolumn{2}{|c|}{ Case 4} & \multicolumn{2}{|c|}{ Case 5} & \multicolumn{2}{|c|}{ Case 6} & \multicolumn{2}{|c|}{ Case 7} \\
\hline & $\mathrm{A}$ & B & $\mathrm{A}$ & $\mathrm{B}$ & A & $\mathrm{B}$ & $\mathrm{A}$ & $\mathrm{B}$ & $\mathrm{A}$ & $\mathrm{B}$ & A & $\mathrm{B}$ & $\mathrm{A}$ & $\mathrm{B}$ \\
\hline & 0 & 0 & 6 & 6 & 12 & 12 & 0 & 0 & 6 & 6 & 12 & 12 & 0 & 0 \\
\hline & 1 & 0,5 & 1 & 0,5 & 1 & 0,5 & 1 & 0,2 & 2 & 0,4 & 2 & 0,4 & 2 & 0,2 \\
\hline & $\begin{array}{l}\downarrow \\
\text { (hol }\end{array}$ & $\begin{array}{l}\text { pain } \\
\text { s) }\end{array}$ & $\begin{array}{l}\downarrow \\
\text { (ho }\end{array}$ & $\begin{array}{l}\text { pain } \\
\text { rs) }\end{array}$ & $\begin{array}{l}\downarrow \\
\text { (ho }\end{array}$ & $\begin{array}{l}\text { pain } \\
\text { s) }\end{array}$ & $\begin{array}{l} \\
\text { (ho }\end{array}$ & $\begin{array}{l}\text { pain } \\
\text { s) }\end{array}$ & $\begin{array}{l}\downarrow \\
\text { (hou }\end{array}$ & $\begin{array}{l}\text { pain } \\
\text { rs) }\end{array}$ & $\begin{array}{l}\downarrow \\
\text { (ho }\end{array}$ & $\begin{array}{l}\text { pain } \\
\text { rs) }\end{array}$ & $\begin{array}{l}\downarrow \\
\text { (hou }\end{array}$ & $\begin{array}{l}\text { pain } \\
\text { rs) }\end{array}$ \\
\hline EI & $5,3^{*}$ & $5,3 *$ & $5,3 *$ & $5,3 *$ & $5,3^{*}$ & $5,3 *$ & $6,6^{*}$ & $6,6^{*}$ & $3,3^{*}$ & $3,3 *$ & $3,3^{*}$ & $3,3^{*}$ & $3,6^{*}$ & $3,6^{*}$ \\
\hline EL & . & $*$ & 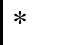 & $*$ & $*$ & & . & * & 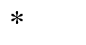 & & $*$ & & & \\
\hline $\mathrm{P}$ & $*$ & $*$ & $*$ & $*$ & $*$ & $*$ & $*$ & $*$ & $*$ & $*$ & $*$ & $*$ & $*$ & $*$ \\
\hline $\mathrm{U}$ & 0 & 16 & 0 & 16 & 2 & 12 & 3,2 & 24 & 0,4 & 18 & 1,6 & 12 & 1,6 & 24 \\
\hline 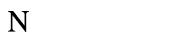 & 4\# & $8 \#$ & $4 \#$ & $8 \#$ & 4 & 8 & 4 & 20 & 2 & 10 & 2 & 10 & 2 & 20 \\
\hline K-S & $\#$ & \# & $\#$ & \# & 4,6 & 6,8 & 5 & 15 & 2,1 & 9,5 & 2,5 & 7,5 & $2 ' 5$ & 15 \\
\hline
\end{tabular}

\begin{tabular}{|c|c|c|c|c|c|c|c|c|c|c|c|c|c|c|}
\hline \multirow{4}{*}{$\begin{array}{l}\text { Patient } \\
\text { Hours } \\
\text { without } \\
\text { pain } \\
\text { Cost/hour }\end{array}$} & \multicolumn{2}{|c|}{ Case 8} & \multicolumn{2}{|c|}{ Case 9} & \multicolumn{2}{|c|}{ Case 10} & \multicolumn{2}{|c|}{ Case 11} & \multicolumn{2}{|c|}{ Case 12} & \multicolumn{2}{|c|}{ Case 13} & \multicolumn{2}{|c|}{ Case 14} \\
\hline & A & $\mathrm{B}$ & A & B & A & $\mathrm{B}$ & A & B & A & B & A & B & A & B \\
\hline & 6 & 6 & 12 & 12 & 0 & 6 & 6 & 12 & 0 & 12 & 0 & 6 & 6 & 12 \\
\hline & 4 & 0,4 & 4 & 0,4 & 1 & 0,5 & 1 & 0,5 & 1 & 0,5 & 1 & 0,2 & 1 & 0,2 \\
\hline & $\begin{array}{l}\downarrow \\
\text { (hol }\end{array}$ & $\begin{array}{l}\text { pain } \\
\text { s) }\end{array}$ & $\begin{array}{l}\downarrow \\
\text { (hol }\end{array}$ & $\begin{array}{l}\text { pain } \\
\text { rs) }\end{array}$ & & $\begin{array}{l}\text { pain } \\
\text { s) }\end{array}$ & $\begin{array}{l}\downarrow \\
\text { (ho }\end{array}$ & $\begin{array}{l}\text { pain } \\
\text { s) }\end{array}$ & $\begin{array}{l}\downarrow \\
\text { (ho }\end{array}$ & $\begin{array}{l}\text { pain } \\
\text { s) }\end{array}$ & $\begin{array}{l}\downarrow \\
\text { (hou }\end{array}$ & $\begin{array}{l}\text { pain } \\
\text { s) }\end{array}$ & $\begin{array}{l}\downarrow \\
\text { (hou }\end{array}$ & $\begin{array}{l}\text { pain } \\
\text { s) }\end{array}$ \\
\hline$\overline{\mathrm{EI}}$ & $1,8^{*}$ & $1,8^{*}$ & $1,8^{*}$ & $1,8^{*}$ & 5,3 & 5 & $\overline{5,3}$ & 5,3 & 5 & 5,3 & & 6,66 & & 6,66 \\
\hline EL & $*$ & * & $*$ & & 7,3 & 1,3 & 7,3 & 1,3 & 8 & 0 & 7,66 & 1,66 & 7,66 & 1,66 \\
\hline 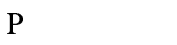 & * & $*$ & $*$ & $*$ & 5,8 & 4,4 & 6 & 4 & 6,4 & 3,2 & 17 & 5,2 & 7,1 & 4,5 \\
\hline 0 & 0,2 & 18 & 0,8 & 12 & 0 & 16 & 2 & 12 & 1 & 12 & $4,4 *$ & $18^{*}$ & $5,6 *$ & $12 *$ \\
\hline $\mathrm{N}$ & 14 & 10 & 1 & 10 & 4* & $8^{*}$ & 4 & 8 & 4 & 8 & * & $*$ & $*$ & $*$ \\
\hline$V$ & 1,05 & $9{ }^{\prime} 5$ & 1,25 & 7,5 & $*$ & $*$ & 4. & 6,8 & 4,6 & 6,8 & 5,5 & 12,5 & 6,1 & 9,25 \\
\hline
\end{tabular}




\begin{tabular}{|c|c|c|c|c|c|c|c|c|c|c|c|c|c|c|}
\hline \multirow{4}{*}{$\begin{array}{l}\text { Patient } \\
\text { Hours } \\
\text { without } \\
\text { pain } \\
\text { Cost/hour }\end{array}$} & \multicolumn{2}{|c|}{ Case 15} & \multicolumn{2}{|c|}{ Case 16} & \multicolumn{2}{|c|}{ Case 17} & \multicolumn{2}{|c|}{ Case 18} & \multicolumn{2}{|c|}{ Case 19} & \multicolumn{2}{|c|}{ Case 20} & \multicolumn{2}{|c|}{ Case 21} \\
\hline & A & $\mathrm{B}$ & A & B & A & $\mathrm{B}$ & A & B & $\mathrm{A}$ & B & A & B & A & B \\
\hline & 0 & 12 & 0 & 6 & 6 & 12 & 0 & 12 & 6 & 0 & 12 & 6 & 12 & 0 \\
\hline & 2 & 0,4 & 2 & 0,2 & 2 & 0.2 & 4 & 0.4 & 1 & 0,5 & 1 & 0,5 & 1 & 0,5 \\
\hline & $\begin{array}{l}\downarrow \\
\text { (hol }\end{array}$ & $\begin{array}{l}\text { pain } \\
\text { s) }\end{array}$ & $\begin{array}{l}\downarrow \\
\text { (hol }\end{array}$ & $\begin{array}{l}\text { pain } \\
\text { rs) }\end{array}$ & $\begin{array}{l}\downarrow \\
\text { (hol }\end{array}$ & $\begin{array}{l}\text { pain } \\
\text { s) }\end{array}$ & $\begin{array}{l}\downarrow \\
\text { (hol }\end{array}$ & $\begin{array}{l}\text { pain } \\
\text { s) }\end{array}$ & $\begin{array}{l}\downarrow \\
\text { (ho }\end{array}$ & pain & $\begin{array}{l}\downarrow \\
\text { (hol }\end{array}$ & $\begin{array}{l}\text { pain } \\
\text { s) }\end{array}$ & $\begin{array}{l}\downarrow \\
\text { (hol }\end{array}$ & $\begin{array}{l}\text { pain } \\
\text { s) }\end{array}$ \\
\hline$\overline{\mathrm{EI}}$ & 5,3 & 5,3 & 3,6 & 3,6 & 3,6 & 3,6 & 1,8 & 1.8 & 5,3 & 5,3 & 5,3 & 5,3 & 5,3 & 5,3 \\
\hline$\Gamma$ & - & 0 & 4 & 0 & 4 & 0 & , & 0 & 3,3 & 9,3 & 3,3 & 9,3 & 1,3 & 13,3 \\
\hline$P$ & 6,4 & 3,2 & 3,7 & 2,8 & 3,75 & 2,5 & 1,9 & 1 & 4,8 & 6,4 & 4,6 & 6,9 & $4 *$ & $8^{*}$ \\
\hline 0 & 2 & 12 & $2,2 *$ & $18^{*}$ & $2,8^{*}$ & $12^{*}$ & 0,8 & 12 & 0 & 16 & 0 & 16 & م & 16 \\
\hline $\mathrm{N}$ & 14 & 8 & * & * & * & $*$ & 1 & 10 & $4 *$ & $8^{*}$ & $4 *$ & $8^{*}$ & * & $*$ \\
\hline & 4,6 & 6,8 & 2,75 & 12,5 & 3,1 & 9,25 & 1,25 & 7,5 & $*$ & $*$ & & $*$ & 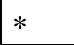 & 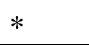 \\
\hline
\end{tabular}

\begin{tabular}{|c|c|c|c|c|c|c|c|c|c|c|c|c|}
\hline \multirow{4}{*}{$\begin{array}{l}\text { Patient } \\
\text { Hours } \\
\text { without } \\
\text { pain } \\
\text { Cost/hour }\end{array}$} & \multicolumn{2}{|c|}{ Case 22} & \multicolumn{2}{|c|}{ Case 23} & \multicolumn{2}{|c|}{ Case 24} & \multicolumn{2}{|c|}{ Case 25} & \multicolumn{2}{|c|}{ Case 26} & \multicolumn{2}{|c|}{ Case 27} \\
\hline & $\mathrm{A}$ & $\mathrm{B}$ & $\mathrm{A}$ & $\mathrm{B}$ & $\mathrm{A}$ & $\mathrm{B}$ & $\mathrm{A}$ & $\mathrm{B}$ & $\mathrm{A}$ & $\mathrm{B}$ & $\mathrm{A}$ & $\mathrm{B}$ \\
\hline & 6 & 0 & 12 & 6 & 12 & 0 & 6 & 0 & 12 & 6 & 12 & 0 \\
\hline & 1 & 0,2 & 1 & 0,2 & 1 & 0,2 & 2 & 0,2 & 2 & 0.2 & & \\
\hline & $\begin{array}{l}\downarrow \\
\text { (hol }\end{array}$ & $\begin{array}{l}\text { pain } \\
\text { rs) }\end{array}$ & $\begin{array}{l}\downarrow \\
\text { (hou }\end{array}$ & $\begin{array}{l}\text { pain } \\
\text { rs) }\end{array}$ & $\begin{array}{l}\downarrow \\
\text { (ho }\end{array}$ & $\begin{array}{l}\text { pain } \\
\text { s) }\end{array}$ & $\begin{array}{l}\downarrow \\
\text { (hol }\end{array}$ & $\begin{array}{l}\text { pain } \\
\text { s) }\end{array}$ & $\begin{array}{l}\downarrow \\
\text { (ho }\end{array}$ & & $\begin{array}{l}\downarrow \\
\text { (hol }\end{array}$ & $\begin{array}{l}\text { pain } \\
\text { s) }\end{array}$ \\
\hline$\overline{\mathrm{EI}}$ & 6,7 & 6,7 & 6,7 & 6,7 & 6,7 & 6,7 & 3,7 & 3,7 & 3,6 & 3,6 & 3,6 & 3,6 \\
\hline EL & 5,7 & 11,7 & 5,3 & 11,3 & 4,7 & 16,7 & 3,1 & 9,1 & 2,5 & 14,5 & 3,1 & 9 \\
\hline$P$ & 6,3 & 8,3 & 6,2 & & 5,7 & 11,5 & 3,5 & 4,7 & 3,3 & 6,7 & 3,5 & 5 \\
\hline $\mathrm{U}$ & 3,2 & 24 & $4,4 *$ & $18^{*}$ & 3,2 & 24 & 1,6 & 24 & 1,6 & 24 & $2,2 *$ & $18 *$ \\
\hline $\mathrm{N}$ & 4 & 20 & $*$ & $*$ & 4 & 20 & 2 & 20 & 2 & 20 & $*$ & $*$ \\
\hline K-S & 5 & 15 & 5,5 & 12,5 & 16 & 15 & 2,5 & 15 & 2,5 & 15 & 2,75 & 12,5 \\
\hline
\end{tabular}




\section{Appendix 2. The problem object of the survey}

\section{Example of the context "years"}

We are going to show you a simplified problem of decision making in health care. You have to allocate a certain amount of money between two hypothetical patients. The solution you give to the problem should depend on your preferences and you should not look for a solution that is objectively the best. We are interested in your opinion about these problems. Thanks a lot for your cooperation.

Assume that there are two patients in a hospital, A and B. A is 20 years old and B is 60 years old. Each of them has a different illness. Both illnesses are lethal in a short period of time. If A and B are not treated they will die in few weeks. If they are treated they will reach, at most, 80 years of age (although everybody knows that people die at different ages, we ask you to assume that they will both live in a similar health state until they are 80 and then will die). Each patient has to receive a different treatment. They have to receive treatment for the rest of their lives and if treatment is stopped they will die. Treatment for patient $\mathrm{A}$ has a annual cost of 1 million pesetas and annual cost for patient $\mathrm{B}$ is 0.2 million. The budget that the hospital can allocate to both patients is of 20 million pesetas and you have to allocate this money between both patients. We are going to show you several potential ways of dividing the money. We would like you to choose the option that is best in your opinion. A certain amount of money that is allocated to each patient, the corresponding increase in life expectancy, and the corresponding age of death characterize each option.

\begin{tabular}{|l|l|l|l|l|l|l|}
\hline Option & $\begin{array}{l}\text { Money A } \\
\text { (million) }\end{array}$ & $\begin{array}{l}\text { Money B } \\
\text { (million) }\end{array}$ & Years A & Years B & $\begin{array}{l}\text { Age of } \\
\text { death for } \\
\text { for }\end{array}$ & $\begin{array}{l}\text { Age of } \\
\text { death for } \\
\text { B }\end{array}$ \\
\hline 1 & 16.67 & 3.33 & 16.67 & 16.67 & 36.67 & 76.87 \\
\hline 2 & 16 & 4 & 16 & 20 & 36 & 80 \\
\hline 3 & 20 & 0 & 20 & 0 & 40 & 60 \\
\hline 4 & 18.74 & 1.26 & 18.74 & 6.3 & 38.74 & 66.3 \\
\hline
\end{tabular}

The best option is (please choose only one)

If you think that there is a better option not given above, please specify it in the next table.

\begin{tabular}{|l|l|l|l|lr|lr|}
\hline $\begin{array}{l}\text { Money A A } \\
\text { (million) }\end{array}$ & $\begin{array}{l}\text { Money B } \\
\text { (million) }\end{array}$ & Years A & Years B & $\begin{array}{l}\text { Age of } \\
\text { death for } \\
\text { Age }\end{array}$ & $\begin{array}{l}\text { of death for } \\
\text { B }\end{array}$ \\
\hline & & & & & \\
\hline
\end{tabular}




\section{Example of the context "hours"}

We are going to show you a simplified problem of decision making in health care. You have to allocate a certain amount of money between two hypothetical patients. The solution you give to the problem should depend on your preferences and you should not look for a solution that is objectively the best. We are interested in your opinion about these problems. Thanks a lot for your cooperation.

Assume that there are two patients in a hospital, A and B. Both suffer from indigestion, which causes them strong headache and sickness. With an appropriate treatment the indigestion will disappear in 24 hours. In the meantime, we have to give them symptomatic treatment to alleviate the symptoms associated with the indigestion (headache and sickness). Patient A has more severe indigestion and will have symptoms during the 24 hours that the indigestion will last. Patient B has less severe indigestion and symptoms will disappear in 12 hours. The medication to be given to the patients to alleviate these symptoms is different for both patients because of their different physiologic characteristics. To eliminate the symptoms for one hour, patient A needs medication that costs 10,000 pesetas. Patient B needs medication that costs 5,000 to be relieved from symptoms during one hour. The hospital can spend 80,000 pesetas to alleviate symptoms of both patients. We will show you different ways of splitting this budget between both patients and you have to choose the option that is the best. These options show the amount of money that each patient will receive, the reduction in the number of hours of pain and discomfort, and the total number of hours without symptoms that each patient will enjoy during the 24 hours that she suffers from indigestion.

\begin{tabular}{|c|c|c|c|c|c|c|}
\hline Options & Money A & Money B & $\begin{array}{l}\downarrow \text { Hours } \\
\text { without } \\
\text { symptoms } \\
\text { A }\end{array}$ & $\begin{array}{l}\downarrow \text { Hours } \\
\text { without } \\
\text { symptoms } \\
\text { B }\end{array}$ & $\begin{array}{l}\text { Total } \\
\text { hours } \\
\text { without } \\
\text { symptoms } \\
\text { A }\end{array}$ & $\begin{array}{l}\text { Total } \\
\text { hours } \\
\text { without } \\
\text { symptoms } \\
\text { B }\end{array}$ \\
\hline 1 & 53,300 & 26,700 & $5 \mathrm{~h} 20^{\prime}$ & $5 \mathrm{~h} 20^{\prime}$ & $5 \mathrm{~h} 20^{\prime}$ & 17h 20' \\
\hline 2 & 20,000 & 60,000 & $2 \mathrm{~h}$ & $12 \mathrm{~h}$ & $2 \mathrm{~h}$ & $24 \mathrm{~h}$ \\
\hline 3 & 40,000 & 40,000 & $4 \mathrm{~h}$ & $8 \mathrm{~h}$ & $4 \mathrm{~h}$ & $20 \mathrm{~h}$ \\
\hline 4 & 45,700 & 34,300 & 4h 34' & $62^{\prime}$ & 4h 34' & 18h 52' \\
\hline 5 & 80,000 & 0 & $8 \mathrm{~h}$ & $\mathrm{Oh}$ & $8 \mathrm{~h}$ & $12 \mathrm{~h}$ \\
\hline 6 & 64,000 & 16,000 & $6 \mathrm{~h} 24^{\prime}$ & $3 \mathrm{~h} 12^{\prime}$ & $6 \mathrm{~h} 24^{\prime}$ & 15h 12' \\
\hline
\end{tabular}
table.

If you think that there is a better option not given above, please specify it in the next

\begin{tabular}{|c|c|c|c|c|c|}
\hline Money A & Money B & \begin{tabular}{|l}
$\downarrow$ Hours \\
without \\
symptoms \\
A
\end{tabular} & \begin{tabular}{|l}
$\downarrow$ Hours \\
without \\
symptoms \\
B
\end{tabular} & $\begin{array}{l}\text { Total } \\
\text { hours } \\
\text { without } \\
\text { symptoms } \\
\text { A }\end{array}$ & $\begin{array}{l}\text { Total } \\
\text { hours } \\
\text { without } \\
\text { symptoms } \\
\text { B }\end{array}$ \\
\hline & & & & & \\
\hline
\end{tabular}




\section{Appendix 3. Results of the survey}

Table 1. Number of people choosing each solution in each case. Life threatening disease context.

\begin{tabular}{|l|ccccccc|c|c|c|c|c|c|c|c|c|}
\hline & Case & Case & Case & Case & Case & Case & Case & Case & Case & Case & Case & Case & Case & Case \\
& 1 & 2 & 3 & 4 & 5 & 6 & 7 & 8 & 9 & 10 & 11 & 12 & 13 & 14 \\
\hline $\mathrm{EI}$ & $38^{*}$ & $49^{*}$ & $42^{*}$ & $29 *$ & $45^{*}$ & $39^{*}$ & $30^{*}$ & 26 & $22^{*}$ & $12^{*}$ & 24 & $36 *$ & $16^{*}$ & 20 \\
$\mathrm{EL}$ & $*$ & $*$ & $*$ & $*$ & $*$ & $*$ & $*$ & 6 & 1 & 2 & 13 & 2 & 9 & 17 \\
$\mathrm{P}$ & $*$ & $*$ & $*$ & $*$ & $*$ & $*$ & $*$ & 17 & 26 & 59 & 13 & 28 & 20 & 6 \\
$\mathrm{U}$ & 5 & 1 & 0 & 3 & $16 \#$ & 19 & $25 \#$ & 4 & $10 \#$ & $5 \#$ & $8 \#$ & $13 \#$ & $13 \#$ & 25 \\
$\mathrm{~N}$ & $35 \#$ & $28 \#$ & $35 \#$ & 26 & $\#$ & 23 & $\#$ & $22^{*}$ & $\#$ & $\#$ & $\#$ & $\#$ & $\#$ & 14 \\
$\mathrm{~K}-\mathrm{S}$ & $\#$ & $\#$ & $\#$ & 11 & 17 & 11 & 18 & $*$ & $*$ & $*$ & 8 & $*$ & $*$ & 6 \\
\hline & 78 & 78 & 77 & 69 & 94 & 92 & 98 & 75 & 59 & 90 & 66 & 79 & 58 & 88 \\
\hline
\end{tabular}

\begin{tabular}{|l|cccccccccccccc|}
\hline & Case & Case & Case & Case & Case & Case & Case & Case & Case & Case & Case \\
& 15 & 16 & 17 & 18 & 19 & 20 & 21 & 22 & 23 & 24 & 25 \\
\hline $\mathrm{EI}$ & 44 & 36 & 15 & 7 & 9 & 1 & 8 & 6 & 8 & 5 & 8 \\
$\mathrm{EL}$ & 0 & 2 & $27 *$ & 20 & 23 & $49 *$ & 24 & 41 & 19 & 16 & 37 \\
$\mathrm{P}$ & 9 & 8 & 16 & 7 & $38^{*}$ & $7 \#$ & 1 & $11 \#$ & 0 & 3 & 2 \\
$\mathrm{U}$ & $13^{*}$ & $15^{*}$ & $*$ & 0 & 2 & 14 & 10 & $19 *$ & 8 & 9 & $20^{*}$ \\
$\mathrm{~N}$ & $*$ & $*$ & $19 \#$ & $35 \#$ & $*$ & $*$ & 30 & $*$ & 30 & 21 & $*$ \\
$\mathrm{~K}-\mathrm{S}$ & 7 & 10 & $\#$ & $\#$ & $*$ & $\#$ & 7 & $\#$ & 12 & 15 & 14 \\
\hline & 73 & 71 & 77 & 69 & 72 & 71 & 80 & 77 & 77 & 69 & 81 \\
\hline
\end{tabular}

The * and the \# symbols indicate solutions that coincide in a certain case. For instance, in case $1, \mathrm{EI}, \mathrm{EL}$, and $\mathrm{P}$ coincide.

Table 2. Number of people choosing each solution in each case. Hours of pain context.

\begin{tabular}{|l|c|c|c|c|c|c|c|c|c|c|c|c|c|c|}
\hline & Case & Case & Case & Case & Case & Case & Case & Case & Case & Case & Case & Case & Case & Case \\
& 1 & 2 & 3 & 4 & 5 & 6 & 7 & 8 & 9 & 10 & 11 & 12 & 13 & 14 \\
\hline $\mathrm{EI}$ & $58^{*}$ & $60 *$ & $67 *$ & $41^{*}$ & $55^{*}$ & $37 *$ & $43 *$ & $55^{*}$ & $54 *$ & 15 & 7 & 4 & 13 & 17 \\
$\mathrm{EL}$ & $*$ & $*$ & $*$ & $*$ & $*$ & $*$ & $*$ & $*$ & $*$ & 47 & 39 & 22 & 28 & 17 \\
$\mathrm{P}$ & $*$ & $*$ & $*$ & $*$ & $*$ & $*$ & $*$ & $*$ & $*$ & 6 & 21 & 21 & 7 & 9 \\
$\mathrm{U}$ & 5 & 2 & 0 & 4 & 5 & 6 & 9 & 3 & 5 & 3 & 1 & 0 & $19 *$ & $13 *$ \\
$\mathrm{~N}$ & $12 \#$ & $10 \#$ & 5 & 15 & 12 & 11 & 17 & 13 & 8 & $4 *$ & 0 & 14 & $*$ & $*$ \\
$\mathrm{~K}-\mathrm{S}$ & $\#$ & $\#$ & 8 & 12 & 1 & 5 & 8 & 11 & 9 & $*$ & 6 & 9 & 12 & 5 \\
\hline & 75 & 72 & 80 & 72 & 73 & 59 & 77 & 82 & 76 & 75 & 74 & 70 & 79 & 61 \\
\hline
\end{tabular}

\begin{tabular}{|l|c|c|c|c|c|c|c|c|c|c|c|c|c|}
\hline & Case & Case & Case & Case & Case & Case & Case & Case & Case & Case & Case & Case & Case \\
24 & 25 & 26 & 27 \\
2 & 15 & 16 & 17 & 18 & 19 & 20 & 21 & 22 & 23 & 24 & 25 \\
\hline EI & 15 & 26 & 13 & 16 & 11 & 6 & 7 & 3 & 3 & 8 & 6 & 10 & 0 \\
$\mathrm{EL}$ & 16 & 7 & 27 & 7 & 34 & 43 & 36 & 24 & 28 & 27 & 26 & 22 & 26 \\
$\mathrm{P}$ & 32 & 27 & 23 & 22 & 4 & 6 & $20 *$ & 8 & 10 & 5 & 1 & 1 & 0 \\
$\mathrm{U}$ & 3 & $5 *$ & 6 & 7 & 7 & 6 & 14 & 15 & $13 *$ & 12 & 7 & 13 & $18^{*}$ \\
$\mathrm{~N}$ & 1 & $*$ & 8 & 5 & $10^{*}$ & $10^{*}$ & $*$ & 15 & $*$ & 14 & 16 & 22 & $*$ \\
$\mathrm{~K}-\mathrm{S}$ & 7 & 11 & 10 & 21 & $*$ & $*$ & $*$ & 22 & 25 & 9 & 19 & 9 & 19 \\
\hline & 74 & 76 & 87 & 78 & 66 & 71 & 77 & 87 & 79 & 75 & 75 & 77 & 63 \\
\hline
\end{tabular}




\section{TABLES}

Table 1. Percentage of people choosing the solutions based on claims. Life threatening disease context in plain letter and hours of pain context in bold letter between brackets.

\begin{tabular}{|c|c|c|c|c|}
\hline & $\begin{array}{l}\text { Difference in } \\
\text { efficiency }\end{array}$ & Equal need & $\begin{array}{l}\text { More needy } \\
\text { less efficient }\end{array}$ & $\begin{array}{l}\text { More needy } \\
\text { More efficient }\end{array}$ \\
\hline $\begin{array}{c}\text { EL } \\
P \\
\text { Both } \\
\end{array}$ & 1 to 2 & 55 [81] & $\begin{array}{c}4[49] \\
46[22] \\
50[71]\end{array}$ & $\begin{array}{c}29[56] \\
10[7] \\
39[64]\end{array}$ \\
\hline $\begin{array}{c}\text { EL } \\
\text { P } \\
\text { Both }\end{array}$ & 1 to 5 & $50[65]$ & $\begin{array}{l}12[\mathbf{2 9}] \\
30[\mathbf{2 2}] \\
42[\mathbf{5 1}]\end{array}$ & $\begin{array}{c}30[36] \\
1[10] \\
34[46]\end{array}$ \\
\hline $\begin{array}{c}\text { EL } \\
\text { P } \\
\text { Both }\end{array}$ & 1 to 10 & $42[65]$ & $\begin{array}{c}8[\mathbf{1 7}] \\
10[\mathbf{3 0}] \\
18[\mathbf{4 7}]\end{array}$ & $\begin{array}{c}32[34] \\
2[1] \\
34[35]\end{array}$ \\
\hline $\begin{array}{l}\text { EL - average } \\
P \text { - average }\end{array}$ & & & $\begin{array}{c}8[32] \\
28[25]\end{array}$ & $\begin{array}{c}30[41] \\
5[6]\end{array}$ \\
\hline
\end{tabular}

Table 2. Percentage of people that chooses the utilitarian solution. Life threatening disease context in plain letter and hours of pain context in bold letter between brackets.

\begin{tabular}{|c|c|c|c|}
\hline $\begin{array}{c}\text { Difference in } \\
\text { efficiency }\end{array}$ & Equal need & $\begin{array}{c}\text { More needy } \\
\text { less efficient }\end{array}$ & $\begin{array}{c}\text { More needy } \\
\text { More efficient }\end{array}$ \\
\hline 1 to 2 & $3[3]$ & $5[2]$ & $1,5[12]$ \\
\hline 1 to 5 & $4[7]$ & $-[4]$ & $16[16]$ \\
\hline 1 to 10 & $21[7]$ & $28[8]$ & $11[13]$ \\
\hline
\end{tabular}


Table 3. Percentage of people favoring the different solutions

\begin{tabular}{|c|c|c|c|c|c|c|c|c|c|c|}
\hline & $\begin{array}{l}\text { choice as } \\
\text { a } \\
\text { principle* }\end{array}$ & & \multicolumn{2}{|l|}{$\begin{array}{l}\text { Case } 4 \\
\text { Years }\end{array}$} & & \multicolumn{2}{|c|}{$\begin{array}{l}\text { Case } 18 \\
\text { Years }\end{array}$} & & \multicolumn{2}{|c|}{$\begin{array}{l}\text { Case } 24 \\
\text { Years }\end{array}$} \\
\hline EI & 12 & & Before\# & After • & & Before & After & & Before & After \\
\hline $\mathrm{U}$ & 4 & EI-EL-P & 42 & 61 & EI & 1 & 4 & EI & 7 & 4 \\
\hline $\mathrm{N}$ & 1 & $\mathrm{U}$ & 4 & 6 & $\mathrm{U}$ & 0 & 12 & $\mathrm{U}$ & 13 & 1 \\
\hline KS & 6 & $\mathrm{~N}$ & 38 & 21 & $\mathrm{~N}-\mathrm{KS}$ & 49 & 14 & $\mathrm{~N}$ & 3 & 27 \\
\hline EL & 33 & $\mathrm{KS}$ & 16 & 12 & EL & 28 & 45 & KS & 21 & 14 \\
\hline $\mathrm{P}$ & 29 & & & & $\mathrm{P}$ & 1 & 24 & EL & 23 & 35 \\
\hline ES & 6 & & & & & & & $\mathrm{P}$ & 4 & 10 \\
\hline
\end{tabular}

* This column reflects the percentage of people that chose each solution as the best general principle to allocate resources.

\# This column reflects the percentage of people that chose each solution before the theoretical explanation

- This column reflects the percentage of people that chose each solution after the theoretical explanation 


\section{FIGURES}

Figure 1. The Bqual Increment and Utilitarian solutions

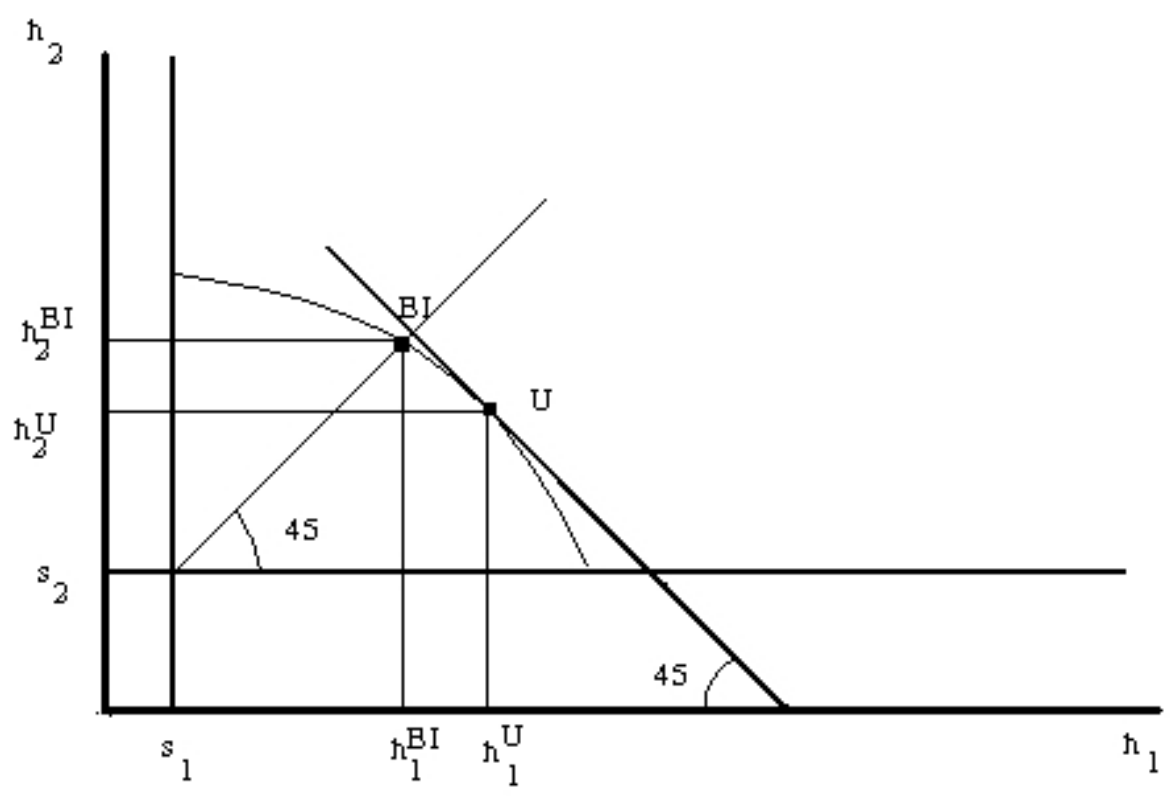


Figure 2. The Nash and Kalai-Smorodinsky solutions

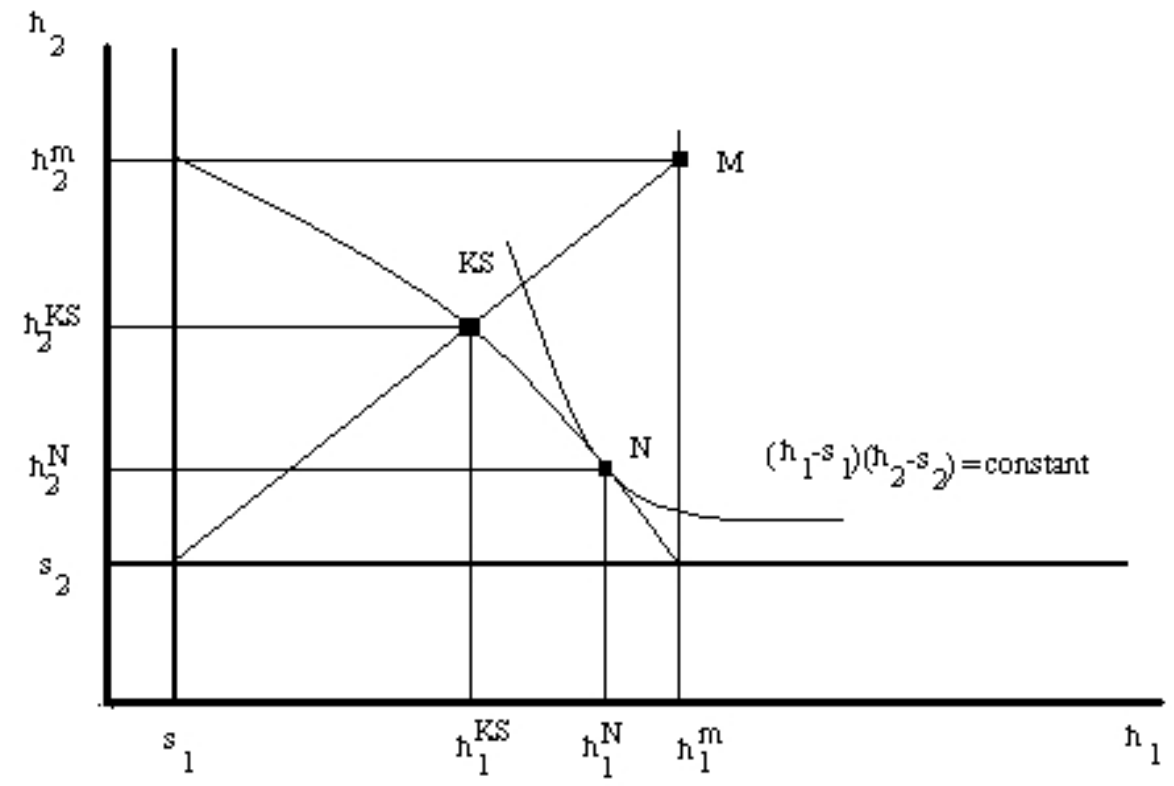


Figure 3. The Proportional and Bqual Loss solutions

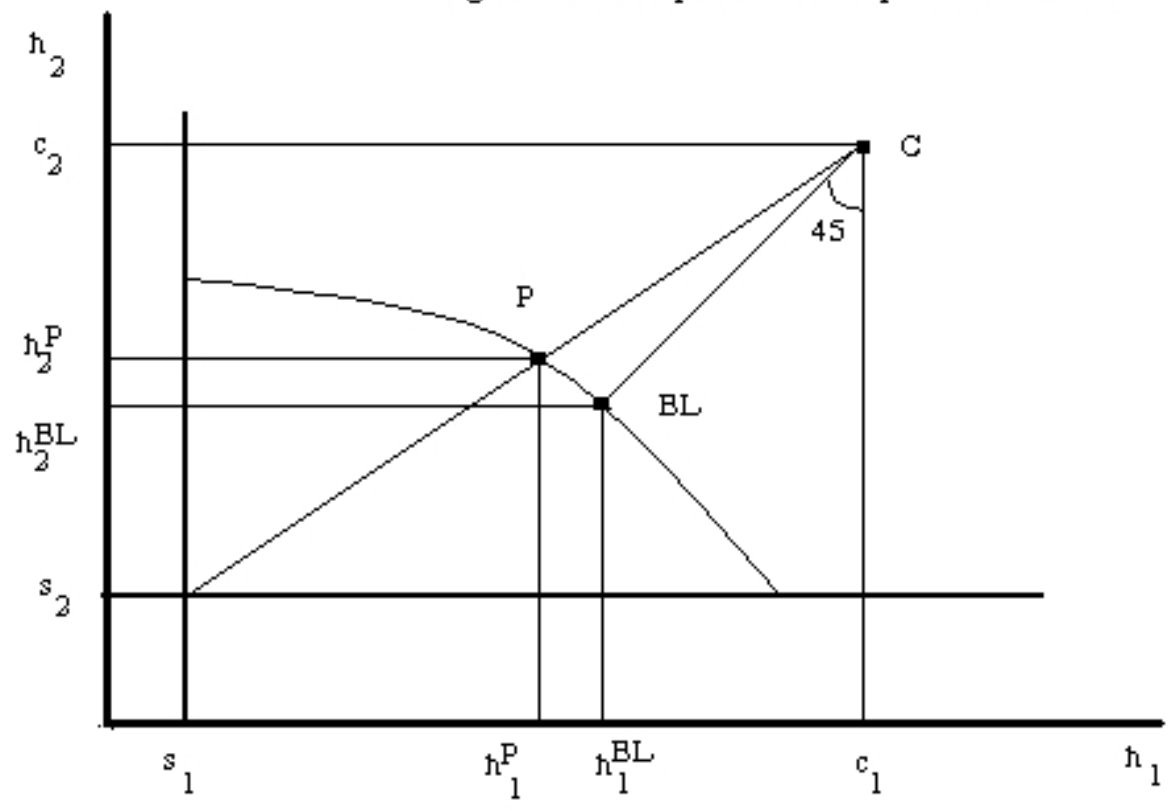

